\title{
Management of pulmonary embolism with rheolytic thrombectomy
}

\author{
Lisa Ferrigno MD, Robert Bloch MD, Judson Threlkeld MD, Thomas Demlow MD, \\ Raman Kansal MD, Riyad Karmy-Jones MD FRCSC
}

\author{
L Ferrigno, R Bloch, J Threlkeld, T Demlow, R Kansal, R Karmy-Jones. \\ Management of pulmonary embolism with rheolytic thrombectomy. \\ Can Respir J 2011;18(4):e52-e58.
}

BACKGROUND: Catheter thrombectomy combining thrombus destruction with local thrombolysis has been used in patients with pulmonary tion, but have contraindications to systemic thrombolytic therapy.

OBJECTIVES: To assess the outcomes of patients who underwent pulmonary embolectomy using a commercially available thrombectomy device. METHODS: A retrospective chart review of patients who underwent pulmonary embolectomy between March 2007 and August 2009 was performed. Patients were classified as having clinical massive or submassive $\mathrm{PE}$, and moderate or severe right ventricular dysfunction. Data collected included pre- and postprocedure shock index (heart rate divided by systolic blood pressure) and mean pulmonary artery pressure.

RESULTS: Sixteen patients with a mean $( \pm$ SD) age of $54.4 \pm 15.8$ years underwent embolectomy. Five had clinical massive PE (two in cardiogenic shock) and three of 11 submassive cases had severe right ventricular dysfunction. All were deemed to have contraindications to systemic lysis. Both shock index $(1.02 \pm 33$ preintervention versus $0.71 \pm 0.2$ postintervention $[\mathrm{P}=0.001])$ and mean pulmonary artery pressure $(34.5 \pm 9.9 \mathrm{mmHg}$ preintervention versus $27.1 \pm 7.1$ postintervention $[\mathrm{P}=0.01])$ improved. In the massive PE group, one patient died and two survivors experienced retroperitoneal bleeding and transient renal failure. At follow-up (17.3 \pm 7.8 months), two patients in the massive PE group demonstrated evidence of mild cor pulmonale.

CONCLUSION: Rheolytic thrombectomy is an effective strategy in managing massive $\mathrm{PE}$, particularly in patients who have well-defined contraindications to systemic lytic therapy. The effectiveness of rheolytic thrombectomy for submassive PE is not as well defined, but warrants a comparison with systemic lytic therapy.

Key Words: Pulmonary embolism; Rheolytic therapy; Thrombectomy embolism (PE) who are unstable or have significant right heart dysfunc-

\author{
La prise en charge de l'embolie pulmonaire par \\ thrombectomie rhéolytique
}

\begin{abstract}
HISTORIQUE : La thrombectomie par cathéter, qui combine la destruction des thrombus avec la thrombolyse localisée, est utilisée chez les patients ayant une embolie pulmonaire (EP) qui sont instables ou présentent une importante dysfonction du cœur droit, mais qui ont des contreindications au traitement thrombolytique systémique.
\end{abstract}

OBJECTIFS : Évaluer les issues des patients qui ont subi une embolectomie pulmonaire au moyen d'un dispositif de thrombectomie commercial.

MÉTHODOLOGIE : Les chercheurs ont procédé à une analyse rétrospective des dossiers de patients qui ont subi une embolectomie pulmonaire entre mars 2007 et août 2009. Les patients ont été classés entre une EP massive ou submassive de forme clinique et une dysfonction ventriculaire droite modérée ou grave. Les données colligées incluaient l'indice de choc avant et après l'intervention (la fréquence cardiaque divisée par la tension artérielle systolique) et la tension artérielle pulmonaire moyenne.

RÉSULTATS : Seize patients d'un âge moyen ( \pm ÉT) de 54,4 $\pm 15,8$ ans ont subi une embolectomie. Cinq avaient une EP massive de forme clinique (deux en choc cardiogène) et trois des 11 cas d'EP submassive avaient une dysfonction ventriculaire droite grave. Tous étaient présumés présenter des contre-indications à la lyse systémique. Les deux indices de choc $(1,02 \pm 33$ avant l'intervention par rapport à $0,71 \pm 0,2$ après l'intervention $[\mathrm{P}=0,001])$ et la tension artérielle pulmonaire moyenne $(34,5 \pm 9,9 \mathrm{mmHg}$ avant l'intervention par rapport à $27,1 \pm 7,1$ après l'intervention $[\mathrm{P}=0,01])$ se sont améliorés. Dans le groupe d'EP massive, un patient est décédé, et deux survivants ont subi une hémorragie rétropéritonéale et une insuffisance rénale transitoire. Au suivi (17,3 $\pm 7,8$ mois), deux patients faisant partie du groupe d’EP massive ont démontré des manifestations bénignes de cœur pulmonaire.

CONCLUSION : La thrombectomie rhéolytique est une stratégie efficace pour prendre en charge l'EP massive, notamment chez les patients qui présentent des contre-indications bien définies à une lyse systémique. Son efficacité pour traiter l'EP n'est pas aussi bien définie, mais mérite une comparaison avec la lyse systémique.

Dulmonary embolism (PE) has been ascribed the cause of death in 1 up to $10 \%$ of patients $(1,2)$. In patients who are in shock, or who experience significant right ventricular dysfunction (RVD), therapy is aimed at reducing the thrombus load as quickly as possible. In the absence of contraindications, guidelines support the use of systemic thrombolytic therapy in these patients (3). However, even when prescreened for absolute contraindications, the major bleeding rate can be as high as $20 \%$, including up to $5 \%$ risk of intracranial hemorrhage (4-6). Surgical embolectomy can be very effective for large central thrombi, but requires a dedicated team and system to be in place (7). Catheter-based technology that combines clot destruction with local thrombolysis (hybrid therapy) offers a relatively simple and quick alternative that can manage both central and peripheral thrombus $(8,9)$. In addition, it may result in improved long-term reduction in pulmonary hypertension and right heart failure (10). In the present case series, we describe our results using the AngioJet (Possis Medical, USA), a rheolytic thrombectomy device, in conjunction with a directed, recombinant tissue plasminogen activator ( $r$-tPA) (Genentech, USA) for the management of PE.

\section{METHODS}

A retrospective chart review of patients who underwent pulmonary embolectomy between March 2007 and August 2009 was performed. The goal was to review the authors' experience with rheolytic thrombectomy, rather than to compare outcomes between thrombectomy and medical management. These patients were referred for pulmonary thrombectomy by the pulmonary critical care team. The American College of Chest Physicians (ACCP) criteria was used to define whether the PE was massive or submassive, and whether RVD was severe or mild (3,11-13). Thus, massive PE was defined as a presenting systolic blood pressure of lower than $90 \mathrm{mmHg}$ or a drop in systolic blood pressure of greater than $40 \mathrm{mmHg}$ for more than $15 \mathrm{~min}$ with no other cause. Cardiogenic shock was defined as evidence of systemic malperfusion and/or the need for inotropic support. Shock index was calculated as heart rate divided by systolic blood pressure. The clinical features listed by the ACCP as being associated with increased likelihood of deterioration include anxiety, 'marked' dyspnea, who 'appear ill' and/or who have low oxygen saturation (lower than 90\%) were recorded when present. Severe RVD was defined as documentation of 
TABLE 1

Clinically submassive pulmonary embolism cases

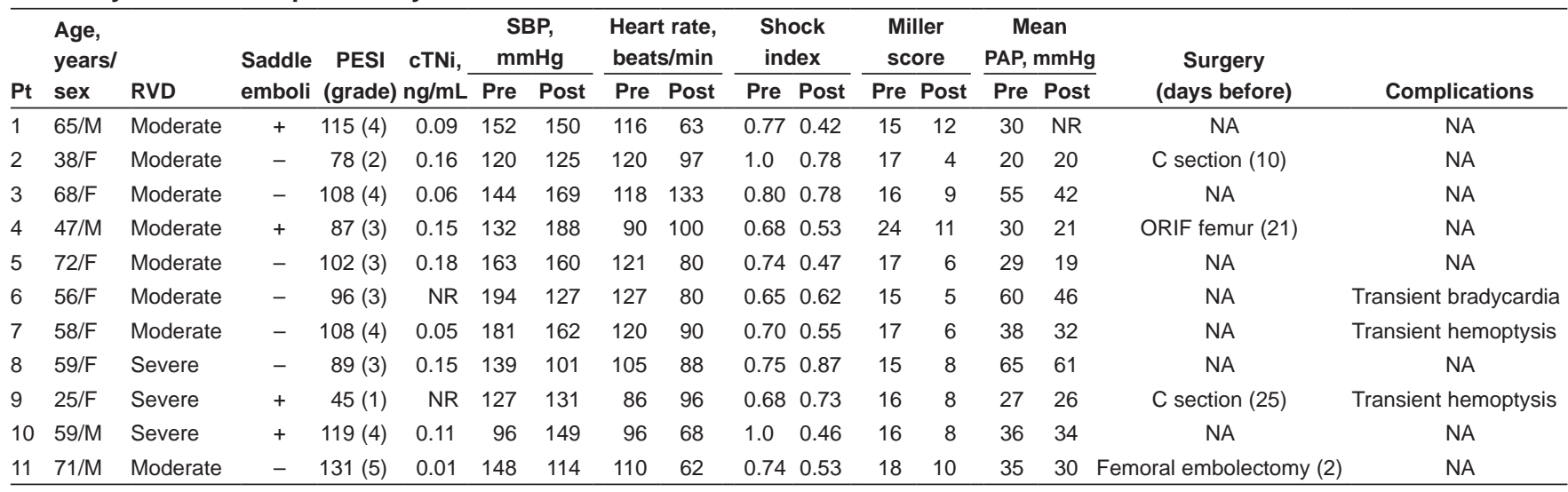

+ Present; - Absent; cTNi Cardiac troponin; F Female; M Male; NA Not applicable; NR Not reported; ORIF Open reduction internal fixation; PAP Pulmonary artery pressure; PESI Pulmonary embolism severity index; Post Postintervention; Pre Preintervention; Pt Patient; RVD Right ventricular dysfunction; SBP Systolic blood pressure

TABLE 2

Clinically massive pulmonary embolism cases

\begin{tabular}{|c|c|c|c|c|c|c|c|c|c|c|c|c|c|c|c|c|}
\hline \multirow[b]{2}{*}{ Pt } & \multirow{2}{*}{$\begin{array}{l}\text { Age, } \\
\text { years/ } \\
\text { sex }\end{array}$} & \multirow{2}{*}{$\begin{array}{l}\text { Saddle } \\
\text { emboli }\end{array}$} & \multirow{2}{*}{$\begin{array}{c}\text { PESI } \\
\text { (grade) }\end{array}$} & \multirow{2}{*}{$\begin{array}{c}\text { cTNi, } \\
\mathrm{ng} / \mathrm{mL}\end{array}$} & \multicolumn{2}{|c|}{$\begin{array}{c}\text { SBP, } \\
\mathrm{mmHg}\end{array}$} & \multicolumn{2}{|c|}{$\begin{array}{l}\text { Heart rate, } \\
\text { beats/min }\end{array}$} & \multicolumn{2}{|c|}{$\begin{array}{l}\text { Shock } \\
\text { index }\end{array}$} & \multicolumn{2}{|c|}{$\begin{array}{l}\text { Miller } \\
\text { score }\end{array}$} & \multicolumn{2}{|c|}{$\begin{array}{c}\text { Mean PAP, } \\
\mathrm{mmHg}\end{array}$} & \multirow{2}{*}{$\begin{array}{c}\text { Surgery } \\
\text { (days before) }\end{array}$} & \multirow[b]{2}{*}{ Complications } \\
\hline & & & & & Pre & Post & Pre & Post & Pre & Post & Pre & Post & Pre & Post & & \\
\hline$\overline{1}$ & $58 / \mathrm{M}$ & + & $168(5)$ & 0.16 & 81 & 144 & 130 & 144 & 1.6 & 1.0 & 23 & 11 & 40 & 30 & $\begin{array}{l}\text { Acetabular } \\
\text { repair (14) }\end{array}$ & $\begin{array}{c}\text { Cardiac arrest-transient, } \\
\text { retroperitoneal bleed, } \\
\text { renal failure resolved }\end{array}$ \\
\hline 2 & $41 / F$ & + & $111(4)$ & 1.2 & 90 & 100 & 85 & 60 & 0.94 & 0.6 & 20 & 14 & 33 & 25 & ORIF ankle (8) & Transient hemoptysis \\
\hline 3 & $50 / \mathrm{M}$ & - & $160(5)$ & 0.15 & 88 & 136 & 120 & 90 & 1.36 & 0.66 & 16 & 6 & 50 & 26 & NA & $\begin{array}{l}\text { Retroperitoneal bleed, } \\
\text { renal failure resolved }\end{array}$ \\
\hline 4 & $77 / F$ & - & $167(5)$ & 0.13 & 70 & 96 & 106 & 115 & 1.5 & 1.2 & 25 & 15 & NR & 21 & NA & $\begin{array}{l}\text { CPR on arrival, death } \\
24 \mathrm{~h} \text { post }\end{array}$ \\
\hline 5 & $25 / \mathrm{M}$ & + & $125(4)$ & 0.05 & 76 & 105 & 198 & 110 & 2.6 & 1.0 & 23 & 12 & 29 & 19 & NA & NA \\
\hline
\end{tabular}

+ Present; - Absent; cTNi Cardiac troponin; CPR Cardiopulmonary resuscitation; F Female; M Male; PESI Pulmonary embolism severity index; NA Not applicable; NR Not reported; ORIF Open reduction internal fixation; PAP Pulmonary artery pressure; Post Postintervention; Pre Preintervention; Pt Patient; SBP Systolic blood pressure

one of the following: right or left ventricular end-diastolic pressure of greater than $1 \mathrm{mmHg}$; right ventricular end-diastolic pressure of greater than $30 \mathrm{mmHg}$; paradoxical right ventricular septal motion; diastolic diameter of right ventricle greater than $30 \mathrm{~mm}$; and hypokenesis of the right ventricular free wall. Moderate RVD was defined as the absence of the above with one of right ventricular end-diastolic pressure of greater than $20 \mathrm{mmHg}$ and lower than $30 \mathrm{mmHg}$, moderate right ventricular dilation and/or right heart strain on electrocardiogram. The Pulmonary Embolism Severity Index (PESI) was calculated for each patient (14). Serum cardiac troponin I (cTNi) was recorded as the level before intervention. The Miller score was calculated retrospectively by a blinded reviewer (15). Saddle emboli was defined as a thrombus in the main pulmonary artery, or a thrombus in both the right and left main pulmonary arteries that occupied more than $50 \%$ of both lumens.

The procedures were performed in the imaging suite. Access was achieved using ultrasound guidance and a $7 \mathrm{Fr}$ sheath advanced into the pulmonary artery. The AngioJet is a $6 \mathrm{Fr}, 100 \mathrm{~cm}$ long dual lumen catheter. The catheter fragments and aspirates thrombi using the Bernoulli principle. One lumen carries high-pressure/high-velocity saline that loops back through the distal end into the second lumen, creating a lowpressure vortex that macerates and aspirates the thrombus (16). The aspirated material is collected in a discharge bag. The injection solution consists of $25 \mathrm{mg} \mathrm{r}-\mathrm{tPA}$ in $250 \mathrm{~mL}$ of normal saline. When using the rheolytic mode, greater than $90 \%$ of the r-tPA is aspirated back. Run times are kept to $5 \mathrm{~s}$ or less to reduce the risk of bradycardia. Thrombolytics can be injected using the power-pulse-spray mode of this device. Mean pulmonary artery pressures (PAPs) were obtained before and at the end of the procedure. All patients received an inferior vena caval filter at the end of the procedure. Transthoracic echocardiogram was repeated $24 \mathrm{~h}$ to $48 \mathrm{~h}$ following intervention.
Approval for the present study was obtained from the institutional review board. Results are expressed as mean \pm SD. Univariate analysis for continuous variables was performed using the independent $t$ test for comparison between groups, while the paired $t$ test was used for comparison within groups of pre- and postintervention parameters. Statistical significance was set at $\mathrm{P}<0.05$. Statistical analysis was performed using SPSS version 14.0 (IBM Corporation, USA).

\section{RESULTS}

During the study period, 374 patients ( 22 of whom were inpatients at the time of diagnosis) were diagnosed with acute PE. Sixteen (4\%) patients underwent pulmonary embolectomy using the AngioJet device in combination with $\mathrm{r}$-tPA infused using the power-pulse-spray mode and formed the study group. The average age of the patients was $54 \pm 15.8$ years, and nine were women. Two were inpatient cases (one medical, one nontrauma surgical) who were on prophylactic anticoagulation. The remainder presented to the emergency department acutely. Two patients were transferred as possible acute myocardial infarction cases. Risk factors for venous thromboembolic disease included the following: obesity (body mass index of greater than $\left.30 \mathrm{~kg} / \mathrm{m}^{2}\right)(\mathrm{n}=7)$; chronic obstructive pulmonary disease (COPD) $(n=5)$; relative immobility $(n=4)$; previous deep venous thrombosis $(n=3)$; coronary artery disease $(\mathrm{n}=2)$; previous cancer $(\mathrm{n}=1)$; and renal insufficiency $(n=1)$. All patients were treated with heparin once the diagnosis was considered, and all underwent computed tomography (CT) angiography to confirm the diagnosis before the interventional team was consulted. All patients underwent transthoracic echocardiography, which in seven cases was performed before CT angiography.

Five patients with clinically massive PE (two in cardiogenic shock) and three of 11 with clinically submassive PE had severe RVD (Tables 1 and 2). Of the eight patients with submassive PE without 
TABLE 3

Comparison between submassive and massive pulmonary embolism (PE) groups and impact of intervention

\begin{tabular}{lcc}
\hline & \multicolumn{2}{c}{ PE group } \\
\cline { 2 - 3 } & Submassive & Massive \\
\hline Saddle emboli, $\mathrm{n}$ & 4 & 3 \\
Age, years & $54.6 \pm 16.4$ & $54.2 \pm 13.5$ \\
Pulmonary embolism severity index & $105.7 \pm 32$ & $125.3 \pm 33.0$ \\
Cardiac troponin I, ng/mL & $0.08 \pm 0.06$ & $0.58 \pm 0.5^{\star}$ \\
Time to catheterization, $\mathrm{h}$ & $21 \pm 26$ & $8 \pm 10^{*}$ \\
Heart rate, beats/min, pre & $109 \pm 13$ & $109 \pm 21^{\star}$ \\
Heart rate, beats/min, post & $91 \pm 27$ & $102 \pm 38$ \\
Systolic blood pressure, mmHg, pre & $134 \pm 18$ & $83 \pm 8^{\star}$ \\
Systolic blood pressure, mmHg, post & $147 \pm 23$ & $120 \pm 24^{\dagger}$ \\
Shock index, pre & $0.82 \pm 0.1$ & $1.3 \pm 0.3^{\star}$ \\
Shock index, post & $0.63 \pm 0.2^{\dagger}$ & $0.8 \pm 0.3^{\dagger}$ \\
Miller score, pre & $17 \pm 3.2$ & $18 \pm 3.4$ \\
Miller score, post & $8.8 \pm 3^{\dagger}$ & $9.5 \pm 4.4^{\dagger}$ \\
Mean pulmonary artery pressure, mmHg, pre & $31 \pm 10.1$ & $40 \pm 6$ \\
Mean pulmonary artery pressure, mmHg, post & $26 \pm 8^{\dagger}$ & $28 \pm 6^{\dagger}$ \\
Intensive care unit length of stay, days & $1.5 \pm 0.8$ & $12.8 \pm 14^{*}$ \\
Hospital length of stay, days & $3 \pm 1.6$ & $17 \pm 17^{\star}$ \\
New York Heart Association class at follow-up & $1.6 \pm 0.8$ & $2.0 \pm 1.0$ \\
\hline
\end{tabular}

Data presented as mean $\pm S D$ unless otherwise indicated. ${ }^{\star} P<0.05$ between groups; ${ }^{\dagger} P<0.05$ preintervention (pre) versus postintervention (post) within groups

significant RVD, all had all four signs of high risk as detailed in the ACCP guidelines, specifically, anxiety, 'marked' dyspnea, 'appeared ill' and/or oxygen saturation lower than $90 \%$. Seven had saddle emboli, five of whom had severe RVD.

Six patients had undergone surgery within 30 days (Tables 1 and 2). Six patients were believed to have absolute contraindications to systemic thrombolytic therapy (surgery within two weeks in four, recent upper gastrointestinal bleed in one and history of severe hypertension in one). In the remaining cases, the pulmonary critical care team believed that the RR of bleeding precluded systemic thrombolytic administration. The indications for intervention included the following: clinically massive PE $(n=5)$; marked RVD $(n=3)$; and moderate RVD with respiratory compromise $(n=8)$. Five of this latter group had undergone systemic heparinization without clinical improvement $(9 \pm 3.5 \mathrm{~h})$. The requesting pulmonary team believed that the patients were marginal clinically, were not candidates for systemic thrombolysis and were at risk for further events that would lead to critical decompensation.

There were distinct differences between the submassive and massive PE groups (Table 3). Compared with the submassive PE group, the clinical massive PE group had a significantly worse shock index, primarily due to lower systolic blood pressure. In addition, the massive PE group had significantly higher levels of cTNi .

Five patients underwent intervention $24 \mathrm{~h}$ to $72 \mathrm{~h}$ following the diagnosis, and the remainder within $6 \mathrm{~h}$. Jugular access was used in nine cases. All procedures were completed within $60 \mathrm{~min}$. The amount of $\mathrm{r}-\mathrm{tPA}$ administered ranged from $10 \mathrm{mg}$ to $20 \mathrm{mg}$.

Of the 358 patients who were not managed by embolectomy, there were $11(3 \%)$ in-hospital fatalities. No patient in this group received systemic thrombolytic therapy. There was one $(6 \%)$ fatality in the study group (Table 2). Considering all patients, there was significant improvements in both shock index $(1.02 \pm 0.33$ preintervention versus $0.71 \pm 0.2$ postintervention $[\mathrm{P}=0.001])$ and mean PAP $(34.5 \pm 9.9 \mathrm{mmHg}$ preintervention versus $27.1 \pm 7.1 \mathrm{mmHg}$ postintervention; $[\mathrm{P}=0.01]$ ) following intervention. Improvements in shock index, mean PAP and Miller scores were more marked in the clinical massive PE group (Table 3). In the submassive PE group, three patients (patients 2, 7 and 9) did not
TABLE 4

Mortality rates based on pulmonary embolism severity index (PESI)

\begin{tabular}{lcc}
\hline & \multicolumn{2}{c}{ Mortality } \\
\cline { 2 - 3 } PESI class & Predicted, \% & Observed, $\mathbf{n} \mathbf{n}$ \\
\hline I & 0 & $0 / 1$ \\
II & 1 & $0 / 1$ \\
III & 3.1 & $0 / 4$ \\
IV & 10.4 & $0 / 6$ \\
V & 24.4 & $1 / 4$ \\
\hline
\end{tabular}

experience marked improvement in PAP, and five patients (patients 3 , 5, 6, 8 and 9) did not exhibit marked improvement in shock index (Table 1). However, by $24 \mathrm{~h}$ to $48 \mathrm{~h}$ follow-up, all were stable and demonstrated echocardiographic improvement. Survival based on PESI class is presented in Table 4.

The majority of complications occurred in the massive PE group (Tables 1 and 2). One patient in the massive PE group experienced a significant bradycardic episode responding to intubation and atropine, and required ventilatory support for six days. One patient in the submassive PE group required intubation postprocedure, but was extubated within $24 \mathrm{~h}$.

The length of follow-up averaged $17.3 \pm 7.8$ months. Of the patients in the submassive PE group, seven were New York Heart Association (NYHA) class 1, three were class 2 and one class 3. Of the four survivors in the massive PE group, two were NYHA class 1, one class 2 and one class 3. All patients who were NYHA class 2 were obese (body mass index of greater than $30 \mathrm{~kg} / \mathrm{m}^{2}$ ), one of whom underwent previous coronary artery stenting, and both who were class 3 had pre-event COPD. Initial follow-up echocardiograms were performed between one and three months in all patients. All patients in the submassive PE group had normal or only mild RVD. Two patients in the massive PE group showed mild RVD on echocardiogram and had evidence of mild cor pulmonale. However, both patients had pre-event comorbidities including COPD and morbid obesity, and one patient had a nonocclusive caval thrombus trapped in the vena cava filter.

\section{DISCUSSION}

PE has been described as the most common, preventable cause of death in hospitalized patients, responsible for up to $10 \%$ of all in-hospital and $0.8 \%$ of postoperative deaths $(1,2)$. Three-month mortality rates of as high as $18 \%$ have been reported (4). Approximately $4 \%$ of survivors develop significant chronic pulmonary hypertension within two years (17). Nationally, the incidence of fatal PE appears to have decreased, possibly due to increased awareness of the importance of prophylaxis and early diagnosis. Some institutions have documented an overall increase in the incidence of $\mathrm{PE}$, which is probably due to increased awareness and diagnosis $(1,18)$.

Acute outcomes are linked to comorbidities, the presence of shock and degree of right heart dysfunction $(3,4,14,19-21)$. The simplest indicator of determining immediate prognosis is the presence of hemodynamic compromise. Patients who present with hemodynamic compromise (ie, clinically massive $\mathrm{PE}$ ) have acute mortality rates ranging between $25 \%$ and $60 \%$, and three-month mortality rates of approximately $50 \%$ among those who survive the initial episode $(4,6,10,22,23)$. Patients who are hemodynamically stable throughout their course have much lower mortality rates, ranging from $1 \%$ to $15 \%$ if all causes are included $(24,25)$.

Prognosis in hemodynamically stable (ie, clinically submassive PE) is linked to the degree of right heart dysfunction (24). Patients with marked RVD have mortality rates that range from $10 \%$ to $17 \%$ in the acute setting $(4,10,24)$. Up to $40 \%$ of patients with submassive PE will have echocardiographic evidence of RVD, with increased mortality (26). In hemodynamically stable patients, evidence of right heart dysfunction based on CT or echocardiographic criteria is associated with 
a 2.4 times increased risk of mortality (12). In the absence of echocardiographic data, electrocardiogram demonstrating right heart strain, CT angiogram demonstrating a right ventricular diameter of $90 \%$ or greater of left ventricular diameter, and/or elevated biomarkers (brain natriuetic peptide-BNP and/or cTNi independently have been associated with increased death and nonfatal complications) $(3,12,23,25,26)$. Bova et al $(25)$ found that among hemodynamically stable patients, the three-month mortality among those with a cTNi level of $0.07 \mathrm{ng} / \mathrm{mL}$ or greater was $21 \%$ versus $3 \%$ if it was lower than $0.07 \mathrm{ng} / \mathrm{mL}(\mathrm{P}<0.01)$.

Relying purely on evidence of RVD as a measure of severity is not uniformly sensitive (27). It has been recognized that even in hemodynamically stable patients, those with anxiety, 'marked' dyspnea, who 'appear ill' and/or have low oxygen saturation are at increased risk of decompensation, death and nonfatal complications (3). A variety of clinical scores have been derived to help determine prognosis at presentation and to determine how aggressive intervention should be. These scores have considerable overlap and variation, and appear to be most useful when integrated into a standard plan of management $(13,20)$. The PESI combines demographics (age and sex), comorbid conditions (cancer, heart failure and/or chronic lung disease) with clinical findings (heart rate, systolic blood pressure, respiratory rate, temperature, mental status and oxygen saturation) into five classes. Class I and II (low risk) have $1.1 \%$ and $3.1 \%$ mortality risk, respectively, class III (intermediate) $6.5 \%$ mortality risk, and class IV and V (high risk) $10.4 \%$ and $24.5 \%$ mortality risk, respectively (14).

The goals of treatment are based on immediately reducing right ventricular outflow obstruction while supporting cardiorespiratory status and, hopefully, preventing long-term sequelae of persistent right heart failure and pulmonary hypertension. The decision of how best to intervene depends on an assessment of hemodynamic stability, RVD, a determination of how rapid the response must be and what the risks of intervention are, given the specific situation.

The mainstay of treatment in hemodynamically stable patients is therapeutic anticoagulation. Park et al (1) reviewed the nationwide incidence of PE between 1998 and 2005, using the Nationwide Inpatient Sample, obtained from the Healthcare Cost and Utilization Project of the Agency for Health Care Research and Quality. Compared with medical patients, surgical patients managed by anticoagulation experienced an overall greater mortality $(10.7 \%$ versus $7.1 \%)$, major bleeding complications $(1.7 \%$ versus $0.4 \%)$ and incidence of heparin-induced thrombocytopenia ( $2 \%$ versus $0.7 \%$ ). The authors hypothesized that these differences could be explained by greater morbidity, risk of bleeding and hesitation to use aggressive anticoagulation among the surgical patients.

Long-term outcomes are also a concern. While the reported incidence of chronic pulmonary hypertension following PE managed by heparin or its equivalent alone is generally believed to be less than $5 \%$, the incidence of pulmonary hypertension when measured using catheter or echocardiogram ranges from $11 \%$ to $69 \%(12,28)$. This raises the issue of defining the degree and significance of RVD at presentation and the role of being more aggressive initially in reducing and preventing distal thrombus burden. Using echocardiograms, Kline et al (28) compared the six-month outcomes of patients with PE managed with heparin alone or heparin plus $\mathrm{r}-\mathrm{tPA}$. The authors concluded that more than $90 \%$ of patients who presented with submassive PE and were managed by heparin alone experienced resolution of right ventricular dilation and hypokenesis at six-month follow-up. Despite this, one-half had unchanged or worse right ventricular systolic pressure often associated with significant exercise intolerance or dyspnea at rest They hypothesized that persistent elevation of right ventricular systolic pressure is maladaptive, particularly when associated with tricuspid regurgitation, leading to a complex of right ventricular damage, pulmonary vasospasm and inflammation related to erythrocyte hemolysis.

Thus, even hemodynamically stable patients with minimal right heart dysfunction are at some risk of early and late-term complications - a risk that increases as the RVD worsens $(10,12,25)$. This has led to increasing emphasis on combining anticoagulation with lytic therapy, particularly in patients with moderate to severe RVD or those whose clinical picture suggests that they may be nearing decompensation (3). The evidence that the benefit of systemic lytic therapy in submassive PE outweighs the risk is not entirely clear, partly because of the wide mix of cases in various reports. It is accepted that systemic $\mathrm{r}$-tPA (or other lytic agents) results in earlier resolution of right heart dysfunction when compared with heparin or its equivalent alone. However, it is not entirely clear whether this results in improved survival $(22,29)$. The risk of fatal or clinically major bleeding with systemic lytic therapy has ranged from $0.6 \%$ to $29 \%$, with higher rates generally being reported for streptokinase than $\mathrm{r}-\mathrm{t} \mathrm{PA}$, and higher rates for longer infusions $(24 \mathrm{~h})$ versus shorter $(2 \mathrm{~h})(3,22,29)$. It should be noted that the data suggesting that $\mathrm{r}-\mathrm{tPA}$ is safer then streptokinase are limited (30). The perceived risk of hemorrhage was one reason that in a recent survey of Pennsylvania hospitals (31) only $2.4 \%$ of patients with PE were treated with thrombolytics. Major bleeding occurred in $5.4 \%$ of patients treated with thrombolytics, and this was associated with $54 \%$ mortality. A recent study (32) proposed that reducing the dose of $\mathrm{r}$-tPA to $50 \mathrm{mg}$ in low body weight individuals may be as efficacious with reduced complication rate.

Several meta-analyses have been performed in an attempt to add clarity; however, they have resulted in somewhat contradictory conclusions. Most studies document a $1 \%$ to $2 \%$ incidence of intracranial hemorrhage (30). The meta-analysis by Agnelli et al (29) found an increased risk of bleeding in the heparin plus systemic lytic group (12.9\% versus $8.6 \%)$, a reduction in death $(4.6 \%$ versus $7.7 \%)$ and a reduction in recurrent PE (6.6\% versus $10.9 \%)$. Overall, the combined treatment group had a significant reduction in the combined end points of death and/or recurrent $\mathrm{PE}$ compared with heparin alone $(10.4 \%$ versus $17.3 \% ; \mathrm{P}=0.03$ ). The study by Tardy et al (27) focused on patients who were clinically submassive and in whom the lytic therapy was $\mathrm{r}$-tPA. They found no overall difference in death and/or recurrent PE (3.5\% with $\mathrm{r}$-tPA versus $4.6 \%$ without), nor major bleeding episodes ( $4.9 \%$ with $\mathrm{r}$-tPA versus $4.6 \%$ without). However, they believed that patients with RVD and elevated levels of cardiac biomarkers were a subgroup that probably would benefit more from systemic lytic therapy. Wan et al (33) also found minimal differences when all patients were considered. The addition of systemic lytic therapy was associated with a trend toward reduced recurrent PE (2.7\% versus $4.3 \%)$, all-cause mortality $(4.3 \%$ versus $5.9 \%)$ and an increase in major bleeding $(9.1 \%$ versus $6.1 \%)$. One possible confounding variable is that women may experience an increased risk of bleeding with diminished benefit (34).

The risk/benefit ratio of adding systemic lytic therapy tends to shift toward favouring more aggressive approaches the 'sicker' the patient is. When Wan et al (33) considered studies that included patients who were hemodynamically unstable, the addition of lytic therapy was associated with a marked reduction in death $(6.2 \%$ versus $12.7 \%)$, a significant reduction in death and/or recurrent PE (9.4\% versus $19 \%)$ and a significant increase in major bleeding $(21.9 \%$ versus $11.9 \%)$. The MAnagement strategies and Prognosis of Pulmonary Embolism-3 (MAPPET-3) study (35) - a prospective randomized trial of heparin plus $r-\mathrm{tPA}$ versus heparin plus placebo alone in clinical submassive PE cases but who had pulmonary hypertension and RVD - found low death rates in both groups (3.4\% in treatment versus $2.2 \%$ in the control groups; $\mathrm{P}=0.73$ ) but a marked reduction in the need to escalate therapy (defined as need for intubation, surgical or catheter embolectomy or late systemic thrombolysis and/or vasopressors) (11\% in treatment versus $25 \%$ in the control groups $[\mathrm{P}=0.0005])$. The same authors previously published data demonstrating a nearly $50 \%$ reduction in mortality rates in the subset of patients with impending right heart failure (36).

Thus, the risks/benefits of systemic lytic therapy are not entirely clear. The ACCP practice guidelines state the following: systemic lytic therapy (intravenous $\mathrm{r}$-tPA $100 \mathrm{mg}$ over $2 \mathrm{~h}$ ) be administered in patients with hemodynamic compromise (Grade of recommendation 1B); systemic lytic therapy should be considered in selected patients who are 

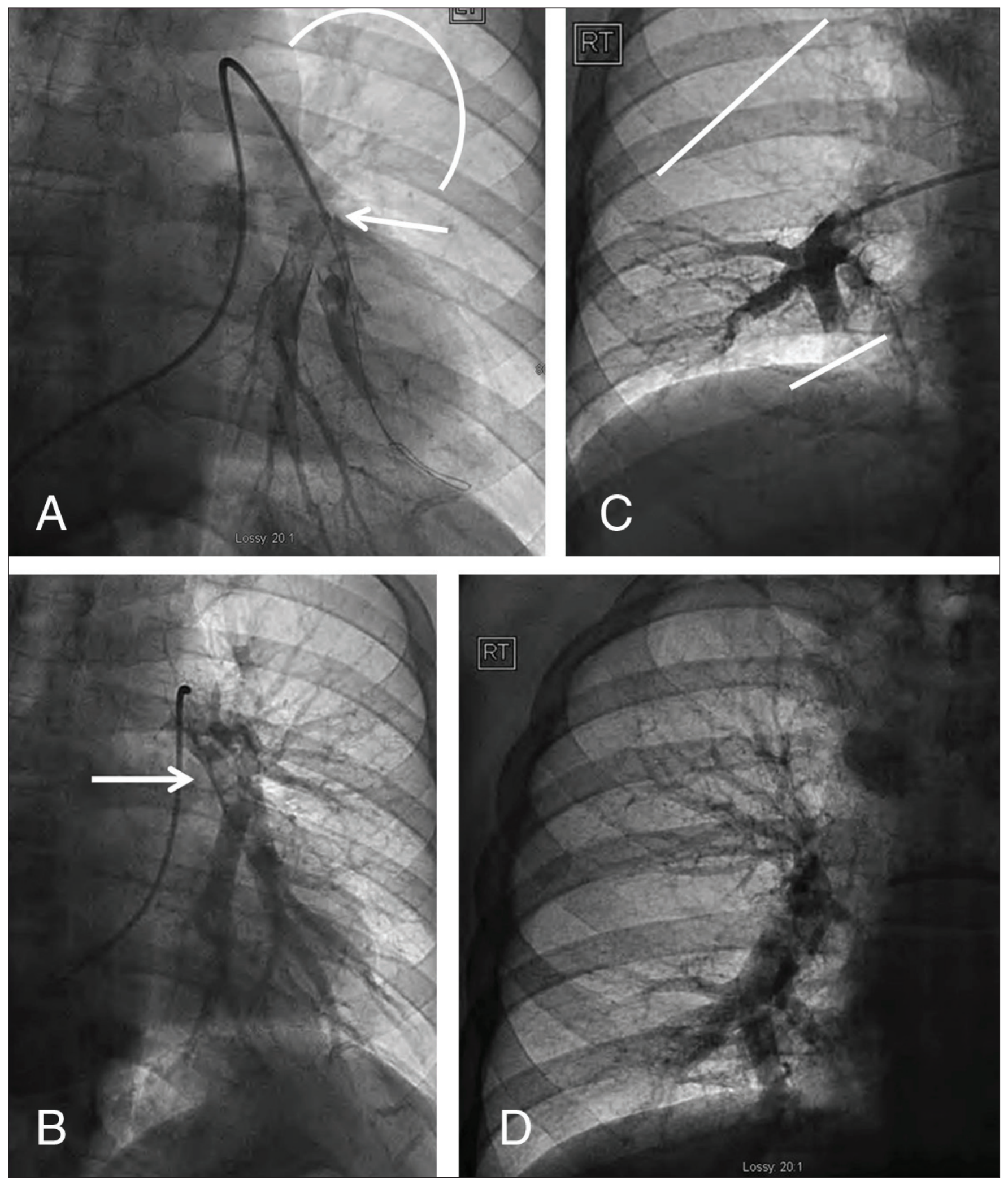

Figure 1) A Relatively central left main pulmonary embolism. Areas of cut of flow indicated by line. Thrombus indicated by arrow. B Postembolectomy of same. Residual thrombus remains (arrow). C Relatively peripheral right pulmonary embolism in the same patient. Areas of cut of flow indicated by lines. D Postembolectomy of same

hemodynamically stable but are judged to be high risk and have low risk of bleeding (Grade of recommendation 2B) (3). There is evidence that systemic lytic therapy is associated with a much more rapid resolution of right heart strain and, possibly, a reduction in late right heart dysfunction.
The ACCP practice guidelines do not recommend surgical or catheter embolectomy as initial management for PE, except in the setting of contraindications or such severe clinical compromise that there is not sufficient time for systemic therapy (Grade of recommendation 2C) (3). 
Contraindications to systemic lysis include trauma or surgery within two weeks, active source or bleeding, diastolic hypertension on presentation and/or intracranial disease $(3,37)$.

Small case reports and series have reported successful surgical embolectomy under emergent circumstances. Probably the largest series was reported by Leacche et al (7). During a four-year period, 47 patients underwent embolectomy using cardiopulmonary bypass, with normothermia and without cardioplegic arrest. The procedures were performed to treat large central thrombus events; $26 \%$ of the patients were in cardiogenic shock while $11 \%$ were in arrest. Indications were contraindications to thrombolysis (45\%), failure of medical management (10\%) and RVD (32\%). There were only three (6\%) operative deaths and the three-year survival rate was $86 \%$; the majority of the late deaths were secondary to cancer. This report demonstrated that if there is a system in place, surgical embolectomy can be very effective for central thrombi. However, there are some patients who may not tolerate the level of systemic heparinization required for cardiopulmonary bypass. In addition, surgical thrombectomy is effective only for large central thrombi.

Catheter embolectomy is attractive because it can limit the systemic impact of thrombolytics, can extract central and peripheral emboli, and can be performed in a rapid and relatively easy manner. Furthermore, it can be performed on patients undergoing cardiopulmonary resuscitation (Figure 1) (38). A variety of techniques have been described, including simple fragmentation. The concern of simply fragmenting thrombus is that while reducing central flow restriction, creating multiple small peripheral emboli may prevent reduction of pulmonary hypertension and, possibly, lead to either a failure of acute and/or late reduction in pulmonary hypertension and right heart failure (39). Catheters that permit thrombus disruption and aspiration appear to be associated with markedly improved results, even if used without local delivery of thrombolytics (6). However, using the catheter to core through thrombus permits locally delivered thrombolytics to work on deeper thrombus layers and potentially have an effect on more distal small-vessel occlusions, resulting in improved acute success, with some evidence that late-term complications are reduced $(6,8,10,39)$. Furthermore, the greater surface area of exposure combined with direct injection allows for much smaller doses to be administered, with greater local and markedly reduced systemic impact (8). Kucher (11) reviewed more than 300 reported cases. Clinical success rates were the lowest with fragmentation techniques; however, all techniques had improved success when combined with local thrombolytic injection. Kuo et al (6) presented a review of 594 patients from 35 studies (six of which were prospective) of catheter-directed thrombectomy. They found that the pooled frequency of success was significantly higher in studies in which at least $80 \%$ of subjects received local thrombolytic therapy during the procedure. The overall clinical success rate was $86.5 \%$, with a major complication rate of $2.4 \%$ and a minor complication rate of $7.9 \%$. While most cases demonstrate almost immediate resolution of right heart strain and pulmonary hypertension, some may take $24 \mathrm{~h}$ to see the clinical benefit; occasionally leaving catheters in place for ongoing thrombolysis has been done.

There are several catheters available that enable combinations of mechanical lysis, aspiration and local thrombolytic injection. Despite the success rate, particularly in unstable patients, it should be noted that use of these devices for pulmonary embolectomy are considered to be off label (6). Specific local complications can include hemoptysis, pulmonary artery perforation, bradycardia and hemoglobinuria. These complications, particularly of bradycardia and hemoglobinuria, appear to be more frequent with the AngioJet than other devices (6). While often attributed to the release of adenosine concurrent with hemolysis, it has also been suggested that bradyarrythmia may be caused by the vibrations created by the drive unit (16). While individual series describing the use of AngioJet in the management of PE reported success rates of $92 \%$ to $94 \%$ with less than $8 \%$ major hemorrhage, and mortality rates of $11 \%$ to $15 \%$, the review by Kuo et al noted major and minor complication rates of $28 \%$ and $40 \%$, respectively $(6,16,40-43)$.
Where follow-up data were available, improvements in right heart function were noted $(16,42)$. Catheters that combine ultrasound wave lysis offer promise of managing more formed thrombus at lower risk, but often require that catheters be left in place for several hours to achieve results $(6,44)$.

Our practice has evolved to using percutaneous embolectomy in patients who are unstable or deemed to be at increased risk of hemodynamic compromise, and who are judged to have contraindications to systemic thrombolysis. In our small series, we found a marked improvement in hemodynamic parameters using the AngioJet. Not unexpectedly, the majority of complications occurred in the most unstable patients. As others have described (16), the clinical benefits may not be immediately apparent, particularly in patients with clinical submassive PE, while the most discernable improvement - albeit accompanied by increased complication rate - was seen in the clinically massive PE group. By keeping run times short, the incidence of bradycardia was low. At follow-up, patients did not appear to experience significant RVD.

Whether at least some of these patients may have benefited from systemic rather than local therapy is not clear. It is also not clear whether patients not referred for embolectomy could have benefited from catheter-based or systemic lysis. It has been suggested that the management of PE be individually determined by each institution, following trauma principles in which selected centres develop a protocol (whether it be systemic medical therapy or embolectomy by surgical or percutaneous means) and act as central referral centres for high-risk patients (6). Our institution has an apparent bias against systemic thrombolytic therapy, which needs to be systematically reevaluated; this bias clearly affects how we can interpret the results as a system. Thus, we cannot prove that our approach is unequivocally superior to systemic thrombolysis, but it appears to be effective, particularly in patients with massive PE, and short outcomes indicate a durable result. While in selected cases, influenced by our selection bias, patients with clinical submassive PE appeared to experience some benefit; however, it is not entirely clear whether systemic lytic therapy could not have achieved the same result. As a result, we are in the process of redefining our indications for choosing between systemic anticoagulation and percutaneous thrombectomy, and revisiting whether our perceived contraindications to systemic thrombolysis are justified.

\section{REFERENCES}

1. Park B, Messina L, Dargon P, Huang W, Ciocca R, Anderson FA. Recent trends in clinical outcomes and resource utilization for pulmonary embolism in the United States: Findings from the nationwide inpatient sample. Chest 2009;136:983-90.

2. Mastracci T, Birch D, Caprini J, Swanstrom L. Laparoscopic surgery compared with open surgery. J Am Coll Surg 2009;209:785-7.

3. Kearon C, Kahn SR, Agnelli G, Goldhaber S, Raskob GE, Comerota AJ. Antithrombotic therapy for venous thromboembolic disease: American College of Chest Physicians evidence-based clinical practice guidelines (8th Edition). Chest 2008;133:454S-545S.

4. Goldhaber SZ, Visani L, De Rosa M. Acute pulmonary embolism: Clinical outcomes in the International Cooperative Pulmonary Embolism Registry (ICOPER). Lancet 1999;353:1386-9.

5. Fiumara K, Kucher N, Fanikos J, Goldhaber SZ. Predictors of major hemorrhage following fibrinolysis for acute pulmonary embolism. Am J Cardiol 2006; 97:127-9.

6. Kuo WT, Gould MK, Louie JD, Rosenberg JK, Sze DY, Hofmann LV. Catheter-directed therapy for the treatment of massive pulmonary embolism: Systematic review and meta-analysis of modern techniques. J Vasc Interv Radiol 2009;20:1431-40.

7. Leacche M, Unic D, Goldhaber SZ, et al. Modern surgical treatment of massive pulmonary embolism: Results in 47 consecutive patients after rapid diagnosis and aggressive surgical approach. J Thorac Cardiovasc Surg 2005;129:1018-23.

8. Tajima H, Murata S, Kumazaki T, et al. Recent advances in interventional radiology for acute massive pulmonary thromboembolism. J Nippon Med Sch 2005;72:74-84. 
9. Tajima H, Murata S, Kumazaki T, et al. Hybrid treatment of acute massive pulmonary thromboembolism: Mechanical fragmentation with a modified rotating pigtail catheter, local fibrinolytic therapy, and clot aspiration followed by systemic fibrinolytic therapy. AJR Am J Roentgenol 2004;183:589-95.

10. Eid-Lidt G, Gaspar J, Sandoval J, et al. Combined clot fragmentation and aspiration in patients with acute pulmonary embolism. Chest 2008;134:54-60.

11. Kucher N. Catheter embolectomy for acute pulmonary embolism. Chest 2007;132:657-63.

12. Sanchez O, Trinquart L, Colombet I, et al. Prognostic value of right ventricular dysfunction in patients with haemodynamically stable pulmonary embolism: A systematic review. Eur Heart J 2008:29:1569-77.

13. Sanchez $\mathrm{O}$, Trinquart $\mathrm{L}$, Caille $\mathrm{V}$, et al. Prognostic factors for pulmonary embolism: The PREP study, a prospective multicenter cohort study. Am J Respir Crit Care Med 2010;181:168-73.

14. Aujesky D, Roy PM, Le Manach CP, et al. Validation of a model to predict adverse outcomes in patients with pulmonary embolism. Eur Heart J 2006;27:476-81.

15. Miller GAH, Sutton GC, Kerr IH, Gibson RV, Honey M. Comparison of streptokinase and heparin in treatment of isolated acute massive pulmonary embolism. Br Med J 1971;2:681-84.

16. Zeni PT Jr, Blank BG, Peeler DW. Use of rheolytic thrombectomy in treatment of acute massive pulmonary embolism. J Vasc Interv Radiol 2003;14:1511-5.

17. Caprini JA. Risk assessment as a guide for the prevention of the many faces of venous thromboembolism. Am J Surg 2010;199:S3-10.

18. Menaker J, Stein DM, Scalea TM. Pulmonary embolism after injury: More common than we think? J Trauma 2009;67:1244-9.

19. Donze J, Le Gal G, Fine MJ, et al. Prospective validation of the Pulmonary Embolism Severity Index. A clinical prognostic model for pulmonary embolism. Thromb Haemost 2008;100:943-8.

20. Jimenez D, Yusen RD. Prognostic models for selecting patients with acute pulmonary embolism for initial outpatient therapy. Curr Opin Pulm Med 2008;14:414-21.

21. Jimenez D, Uresandi F, Otero R, et al. Troponin-based risk stratification of patients with acute nonmassive pulmonary embolism: Systematic review and metaanalysis. Chest 2009;136:974-82.

22. Konstantinides $\mathrm{S}$. Should thrombolytic therapy be used in patients with pulmonary embolism? Am J Cardiovasc Drugs 2004;4:69-74.

23. Kucher N, Rossi E, De Rosa M, Goldhaber SZ. Massive pulmonary embolism. Circulation 2006;113:577-82.

24. Kucher N, Rossi E, De Rosa M, Goldhaber SZ. Prognostic role of echocardiography among patients with acute pulmonary embolism and a systolic arterial pressure of $90 \mathrm{~mm} \mathrm{Hg}$ or higher. Arch Intern Med 2005;165:1777-81.

25. Bova C, Pesavento R, Marchiori A, et al. Risk stratification and outcomes in hemodynamically stable patients with acute pulmonary embolism: A prospective, multicentre, cohort study with three months of follow-up. J Thromb Haemost 2009;7:938-44.

26. Cavallazzi R, Nair A, Vasu T, Marik PE. Natriuretic peptides in acute pulmonary embolism: A systematic review. Intensive Care Med 2008;34:2147-56

27. Tardy B, Venet C, Zeni F, Coudrot M, Guyomarc'h S, Mismetti P. Short term effect of recombinant tissue plasminogen activator in patients with hemodynamically stable acute pulmonary embolism: Results of a meta-analysis involving 464 patients. Thromb Res 2009;124:672-7.
28. Kline JA, Steuerwald MT, Marchick MR, Hernandez-Nino J, Rose GA. Prospective evaluation of right ventricular function and functional status 6 months after acute submassive pulmonary embolism: Frequency of persistent or subsequent elevation in estimated pulmonary artery pressure. Chest 2009;136:1202-10.

29. Agnelli G, Becattini C, Kirschstein T. Thrombolysis vs heparin in the treatment of pulmonary embolism: A clinical outcome-based meta-analysis. Arch Intern Med 2002;162:2537-41.

30. Davidson BL. Half the dosage, similar efficacy, less bleeding: The new tissue plasminogen activator regimen for pulmonary embolism? Chest 2010;137:245-7.

31. Ibrahim SA, Stone RA, Obrosky DS, Geng M, Fine MJ, Aujesky D. Thrombolytic therapy and mortality in patients with acute pulmonary embolism. Arch Intern Med 2008;168:2183-90; discussion 2191-2.

32. Wang C, Zhai Z, Yang Y, et al. Efficacy and safety of low dose recombinant tissue-type plasminogen activator for the treatment of acute pulmonary thromboembolism Chest 2010;137:254-62.

33. Wan S, Quinlan DJ, Agnelli G, Eikelboom JW. Thrombolysis compared with heparin for the initial treatment of pulmonary embolism: A meta-analysis of the randomized controlled trials. Circulation 2004;110:744-9.

34. Geibel A, Olschewski M, Zehender M, et al. Possible gender-related differences in the risk-to-benefit ratio of thrombolysis for acute submassive pulmonary embolism. Am J Cardiol 2007;99:103-7.

35. Konstantinides S, Geibel A, Heusel G, Heinrich F, Kasper W. Heparin plus alteplase compared with heparin alone in patients with submassive pulmonary embolism. N Engl J Med 2002;347:1143-50

36. Konstantinides S, Geibel A, Olschewski M, et al. Association between thrombolytic treatment and the prognosis of hemodynamically stable patients with major pulmonary embolism: Results of a multicenter registry. Circulation 1997;96:882-8.

37. Kanter DS, Mikkola KM, Patel SR, Parker JA, Goldhaber SZ. Thrombolytic therapy for pulmonary embolism. Frequency of intracranial hemorrhage and associated risk factors. Chest 1997;111:1241-5.

38. Fava M, Loyola S, Bertoni H, Dougnac A. Massive pulmonary embolism: Percutaneous mechanical thrombectomy during cardiopulmonary resuscitation. J Vasc Interv Radiol 2005;16:119-23.

39. Nakazawa K, Tajima H, Murata S, Kumita SI, Yamamoto T, Tanaka K. Catheter fragmentation of acute massive pulmonary thromboembolism: Distal embolisation and pulmonary arterial pressure elevation. Br J Radiol 2008;81:848-54.

40. Spies C, Khandelwal A, Smith TH, Jolly N, Kavinsky CJ. Percutaneous mechanical thrombectomy for massive pulmonary embolism using a conservative treatment strategy. J Interv Cardiol 2008;21:566-71.

41. Chechi T, Vecchio S, Spaziani G, et al. Rheolytic thrombectomy in patients with massive and submassive acute pulmonary embolism. Catheter Cardiovasc Interv 2009;73:506-13.

42. Chauhan MS, Kawamura A. Percutaneous rheolytic thrombectomy for large pulmonary embolism: A promising treatment option. Catheter Cardiovasc Interv 2007;70:121-8.

43. Margheri M, Vittori G, Vecchio S, et al. Early and long-term clinical results of AngioJet rheolytic thrombectomy in patients with acute pulmonary embolism. Am J Cardiol 2008;101:252-8.

44. Chamsuddin A, Nazzal L, Kang B, et al. Catheter-directed thrombolysis with the Endowave system in the treatment of acute massive pulmonary embolism: A retrospective multicenter case series. J Vasc Interv Radiol 2008;19:372-6. 


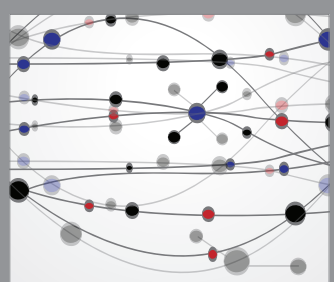

The Scientific World Journal
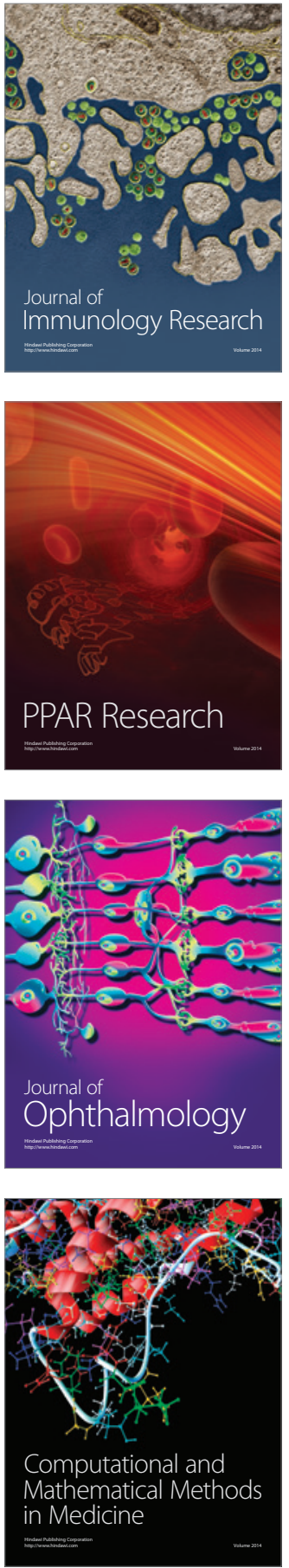

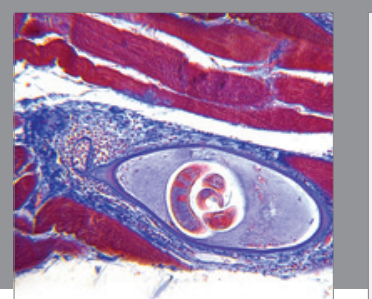

Gastroenterology Research and Practice

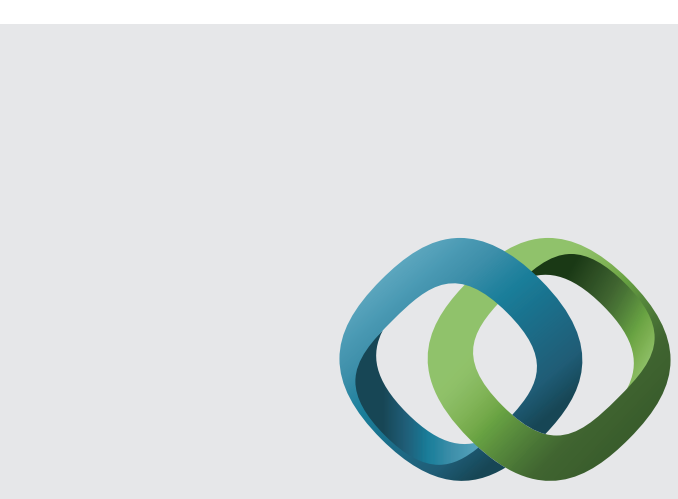

\section{Hindawi}

Submit your manuscripts at

http://www.hindawi.com
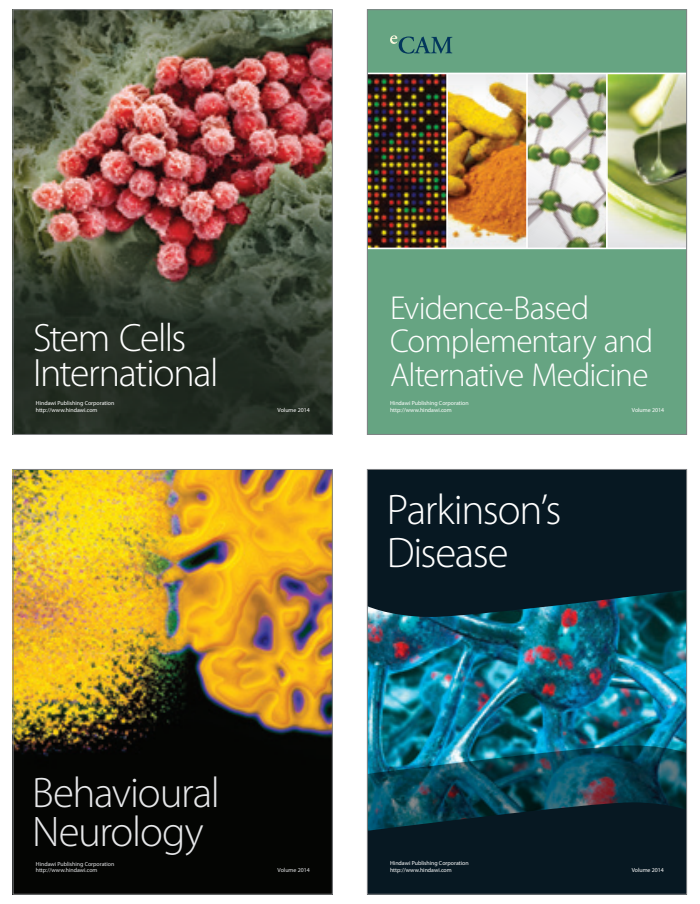
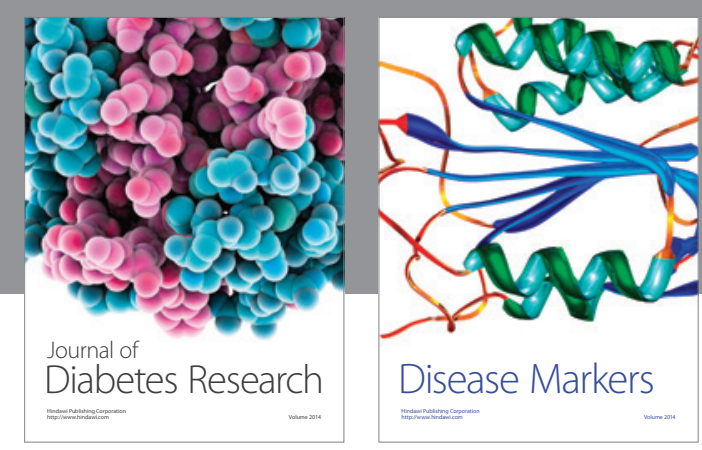

Disease Markers
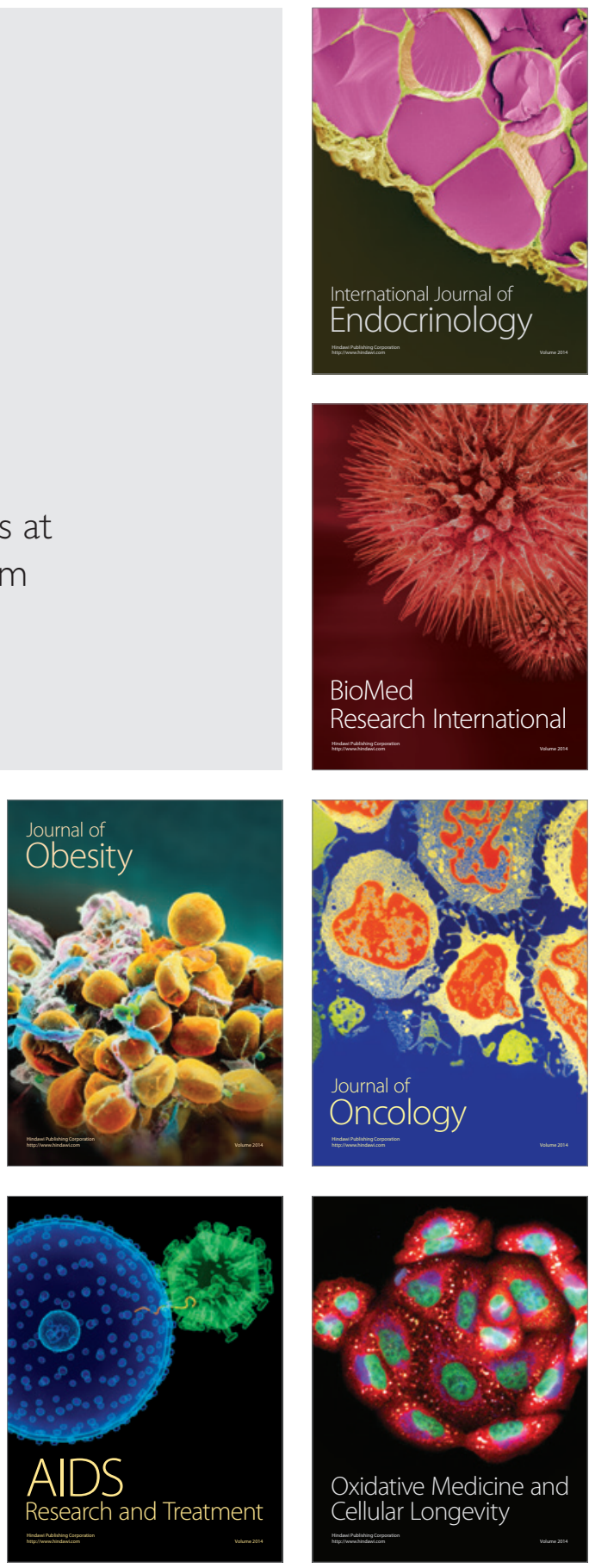